This book is an interesting historical survey against an ever-changing social and economic background, with sufficient technological information for the reader to appreciate the development of this rather exotic industry from humble beginnings.

R. W. K. HONEYCOMBE

\section{THE RETRIEVAL OF PUBLISHED INFORMATION}

Retrieval Guide to Thermophysical Properties Research Literature

Vol. 1. Edited by Y. S. Touloukian. Book 1, Part A: Guide to Substance Classification and Numerical Codes. Book 1, Part B : Dictionary of Synonyms and Trade Names. Book 1, Part C : Directory of Substances. Pp. xii +1352 . Book 2 : Classified Search Index. Pp. vii +169 . Book 3: Master Bibliography; Author Index. Pp. ix +372. (New York : McGraw-Hill Book Company, Inc.; London: McGraw-Hill Publishing Co., Ltd., 1960.) $£ 4610 \mathrm{~s}$. $0 \mathrm{~d}$.

1 HIS massive work constitutes the first fruits of one particular plan to master the enormous wealth of knowledge which is the outcome of scientific research. The general problem is well known. As laboratories are multiplied and scientists grow in numbers, any use of the information they obtain is liable to become increasingly patchy, because it is becoming increasingly difficult to locate every mention of a subject in published scientific literature. Often much of the information available has, in fact, not been used because its existence was not known. In quite a few cases there is wasteful duplication of effort in planning research to obtain scientific information that is already adequately available, for the purpose in view, in published literature.

The Thermo-Physical Properties Research Centre, Purdue University, has been working since 1957 to overcome the present limitations to the use of acquired knowledge in a strictly defined and fairly narrow field of thermophysical properties of matter. These aim to be those of importance primarily to engineers, and these three books of Volume 1 are the first publication from this Centre. They deal with 10,000 references concerning the thermal conductivity, specific heat, viscosity, emissivity and related optical properties, diffusion coefficient, and Prandtl number of a long list of materials. By the time Volume 3 is published, the aim is to include linear and cubical coefficients of thermal expansion surface tension, vapour pressure and P.V.T. data, a group of derived thermodynamic parameters, latent heats of fusion, critical and phase transformation constants, thermo-electric constants, and electrical conductivity.

One of the main goals of this Retrieval Guide is to reach the ultimate in comprehensiveness of coverage of information about these thermophysical properties, part of which may never be found by merely consulting the abstracting journals. To reach this goal, a high level of financial expenditure and intellectual effort has obviously been involved. An interesting feature is that unlike other collections of similar data, this group of books develops its own method of coding substances, which needs to be mastered carefully to use the interlocking method of coding properties and of the 10,000 literature references given in Book 3 of Volume 1.
It need scarcely be stated that effective retrieval systems are becoming of increasing importance for applied and even for pure science. Before deciding just how good the present system will prove to be, one would wish to proceed experimentally, and to expose one or two working librarians to the use of this volume by comparison with other methods of retrieving desired information from scientific literature.

Sampling suggests that the present publication is likely to prove most useful and to repay handsomely its initial cost for central libraries that deal with many inquiries. For smaller libraries, appropriate, if clumsier, books of tables of physical properties are likely to remain more acceptable for some time to come, even though they suffer from the grave defect of lack of comprehensiveness. The standing of the Research Centre is a warrant for the continuation of this series in further volumes. Their production is of high quality, and the series should prove itself to be increasingly indispensable as more volumes increase the range and dates of publication of the information covered. A. R. UBBELOHDE

\section{DICTIONARY OF THE FUNGI}

Ainsworth and Bisby's Dictionary of the Fungi Fifth edition by Dr. G. C. Ainsworth. Pp. viii +547 . (Kew, Surrey : Commonwealth Mycological Institute, 1961.) $30 s$.

ANSWORTH and Bisby's Dictionary of the A Fungi has been regarded as a major work of scholarship since the publication of the first edition in 1943. It has earned for itself a place on the bookshelves of all interested in the study of fungi, and so the appearance of the fifth edition is warmly welcomed by mycologists and plant pathologists alike.

The new edition resembles closely the previous one. In the dictionary proper, which occupies 440 pages, the information is organized under headings arranged alphabetically on the lines of Willis's Dictionary of the Flowering Plants and Ferns. More than 5,000 corrections and alterations have been made to the text of the fourth edition, and much new material has been added. The inclusion of 500 more generic names than in the fourth edition ensures that most genera included in the Index of Fungi up to the end of 1960 are to be found in the Dictionary. The taxonomic position of each genus is indicated, together with the number of species in a genus and their distribution. Full attention is paid to synonyms. Excellent short accounts are provided of the chief families, orders and classes of Fungi and of bacteria and lichens. Definitions are given of many terms used in mycology and plant pathology, while the general articles on such subjects as collection and preservation of fungi, the genetics, nutrition, and phylogeny of fungi are valuable. Throughout the text there are numerous references to appropriate literature.

Following the alphabetical dictionary, 55 pages are devoted to listing the genera of fungi by classes, orders and sometimes by families. A revised key to the families of fungi by G. W. Martin occupies 21 pages. A new set of drawings illustrating fungal structure and terminology is provided.

The Dictionary of Fungi may be regarded as a mine of carefully compiled and well-presented information, being undoubtedly one of the landmarks of mycology. The new edition is good value at the price of thirty shillings.
JOHN COLHOUN 